\title{
Self-reflections after disbandment of palliative care unit during COVID-19 pandemic
}

Hong Kong Med J 2020;26:463

https://doi.org/10.12809/hkmj208654

To the Editor-With large number of deaths in many countries owing to the coronavirus disease 2019 (COVID-19) pandemic, there is a place for palliative care to alleviate suffering and uphold dignity for these patients. ${ }^{1}$ However, the small number of deaths and the primary goal to save lives has limited the referral of patients with COVID-19 in Hong Kong for palliative care. Nevertheless, medical professionals should be well prepared to serve those who would die of COVID-19 as well as from unrelated causes. ${ }^{2}$

Without palliative care units, although patients with advanced life-limiting illnesses could be admitted to acute medical beds with support from the palliative consultative service, the aggressiveness of medical treatment and provision of compassionate care might not be appropriate in acute settings. This can jeopardise the quality of care, especially for patients with complex needs, challenging symptom burden, and complicated grieving families. Thus, both palliative in-patient and consultative services are complementary and both are needed in acute hospitals. ${ }^{3}$ There is ample evidence that palliative care provides good outcomes, including better quality of life, shortened length of stay in hospital, increased home death, and more cost-effective acute care. ${ }^{4-6}$ Deprioritising palliative care would imply that the local health authority overlooks the holistic needs of people with life-limiting illnesses.

The initial strategy adopted by the Hospital Authority for quarantining all patients with COVID-19 in acute hospitals, regardless of their disease severity, was successful in containing the spread of virus. However, for patients with COVID-19 and only minor or no symptoms, compulsory home or camp quarantine with ambulatory medical support may achieve equal success, sparing the wellequipped cohort wards and intensive care units for those in serious and critical conditions, without sacrificing patients with other medical conditions.

A blanket method of rationing in which individuals are categorised according to factors such as age, physical or mental disability, or those under palliative care, should not be adopted during a pandemic. ${ }^{7,8}$ Categorical exclusions may be interpreted by the public to mean that certain groups of patient are "not worth treating", leading to the perception of unfairness and distrust. Palliative care patients are often the most vulnerable and neglected group in the medical field. Nevertheless, palliative care is about more than medical treatment. A case- by-case approach is a better and more humane way to preserve the dignity of all groups of patients.

\section{Author contributions}

The author drafted the letter. The author approved the final version for publication and takes responsibility for its accuracy and integrity.

\section{Conflicts of interest}

The author declared no conflicts of interest for the authorship and publication of this letter.

\section{Funding/support}

This letter received no specific grant from any funding agency in the public, commercial, or not-for-profit sectors.

PT Lam *, MB, ChB, FHKAM (Medicine)

Department of Medicine and Geriatrics, United Christian Hospital, Hong Kong

*Corresponding author: lampt@ha.org.hk

\section{References}

1. Humanitarian Health Ethics Research Group. Alleviating suffering and upholding dignity in the midst of CoViD-19 response: a place for palliative care. 31 Mar 2020. Available from: https://www.phpc.cam.ac.uk/pcu/files/2020/04/ PallcareCovid_Recommendations_FINAL.pdf. Accessed 30 Apr 2020.

2. Downar J, Seccareccia D, Associated Medical Services Inc. Educational Fellows in Care at the End of Life. Palliating a pandemic: "All patients must be cared for". J Pain Symptom Manage 2010;39:291-5.

3. Gaertner J, Frechen S, Sladek M, Ostgathe C, Voltz R. Palliative care consultation service and palliative care unit: why do we need both? Oncologist 2012;17:428-35.

4. Eti S, O'Mahony S, McHugh M, Guilbe R, Blank A, Selwyn P. Outcomes of the acute palliative care unit in an academic medical center. Am J Hosp Palliat Care 2014;31:380-4.

5. Grogan E, Paes P, Peel T. Excellence in cost-effective inpatient specialist palliative care in NHS-a new model. Clin Med (Lond) 2016;16:7-11.

6. Hui D, Elsayem A, Palla S, et al. Discharge outcomes and survival of patients with advanced cancer admitted to an acute palliative care unit at a comprehensive cancer center. J Palliat Med 2010;13:49-57.

7. Daly DJ. Guidelines for rationing treatment during the COVID-19 crisis: a catholic approach. Health Prog 2020;101. Available from: https://www.chausa.org/ publications/health-progress/current-issue. Accessed 30 Apr 2020

8. Emanuel EJ, Persad G, Upshur R, et al. Fair allocation of scarce medical resources in the time of COVID-19. N Engl J Med 2020;382:2049-55. 